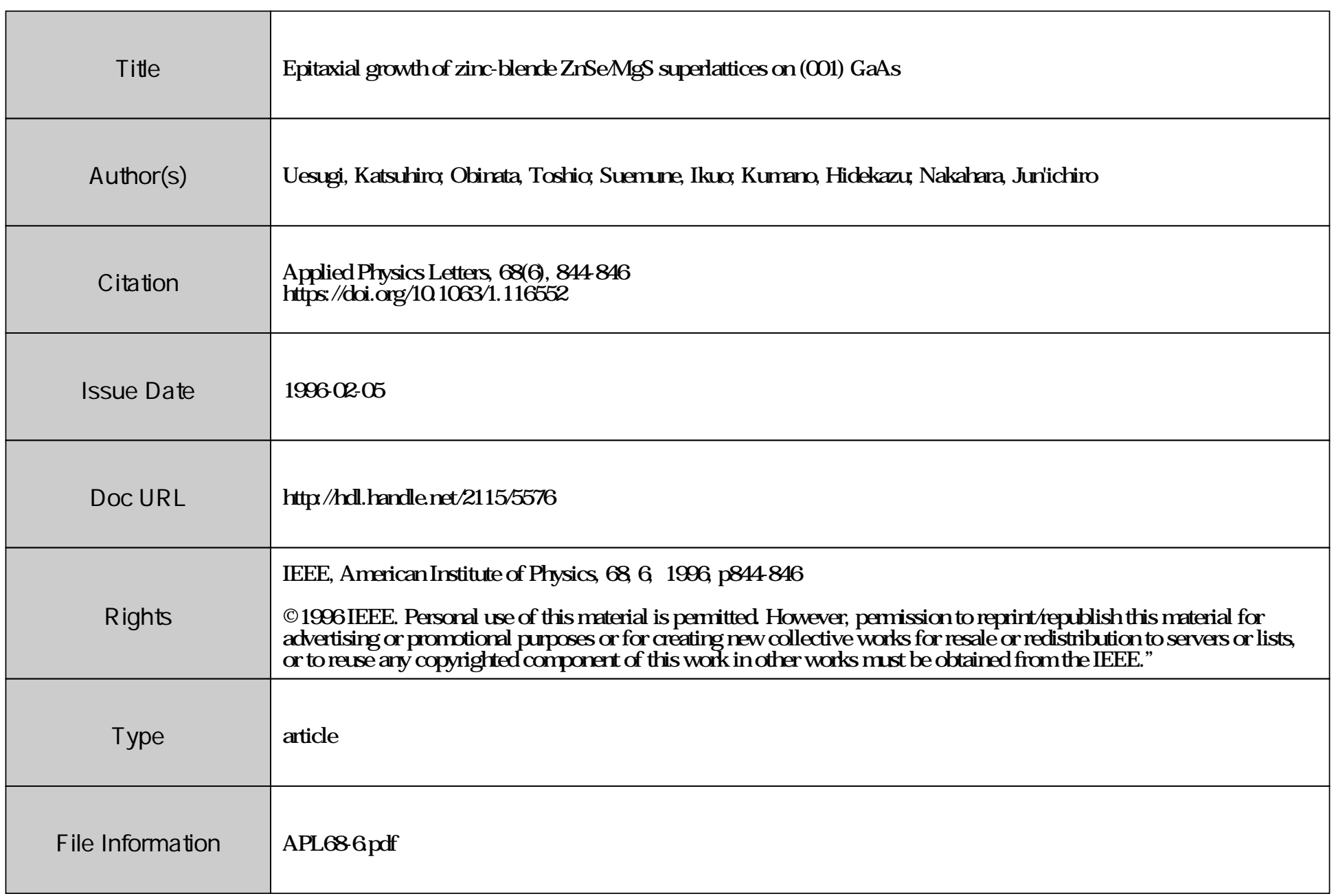

Instructions for use 


\title{
Epitaxial growth of zinc-blende ZnSe/MgS superlattices on (001) GaAs
}

\author{
Katsuhiro Uesugi, Toshio Obinata, and Ikuo Suemune \\ Research Institute for Electronic Science, Hokkaido University, Sapporo 060, Japan
}

Hidekazu Kumano and Jun'ichiro Nakahara

Faculty of Science, Hokkaido University, Sapporo 060, Japan

(Received 18 September 1995; accepted for publication 2 December 1995)

\begin{abstract}
We report the growth of zinc-blende $\mathrm{ZnSe} / \mathrm{MgS}$ superlattices (SLs) on GaAs (001) substrates. The SLs were grown with metalorganic vapor phase epitaxy by selecting appropriate precursors for $\mathrm{Mg}$ and $\mathrm{S}$. MgS naturally forms rocksalt structures, but zinc-blende $\mathrm{MgS}$ layers were grown. The lattice constant of $\mathrm{MgS}$ was estimated to be $5.59 \AA$. X-ray diffraction measurements show that the $\mathrm{ZnSe} / \mathrm{MgS} \mathrm{SLs}$ are grown coherently to the GaAs substrates up to the total thicknesses of $\sim 3000$ Å. (C) 1996 American Institute of Physics. [S0003-6951(96)04506-8]
\end{abstract}

Wide band gap II-VI semiconductor superlattices (SLs) have attracted much attention for realizing blue/green light emitting devices. It is well known that the band offset plays an important role in determining the characteristics of heterostructures. However, most of II-VI heterostructures proposed up to now have band offsets localized to either conduction or valence band edges. In the case of $\mathrm{ZnSe} / \mathrm{ZnSSe}$ SLs, the band offset is localized to valence bands, while the conduction band discontinuity is very small. ${ }^{1}$ For $\mathrm{ZnMnSe} /$ AnMnSe/ZnSe SLs, the heterojunctions exhibit very small valence band offsets. ${ }^{2}$ Recently II-VI compound semiconductors containing group-IIA elements like $\mathrm{Mg}$ are expected to be the most promising materials to realize heterostructures. ${ }^{3-8}$ In particular, $\mathrm{ZnMgSSe}{ }^{3-5,7}$ has been extensively studied since $\mathrm{Zn}(\mathrm{Cd}) \mathrm{Se} / \mathrm{ZnMgSSe}$ heterostructures can confine both electrons and holes. Nakayama et al. demonstrated first continuous-wave operation of blue-green laser diodes using $\mathrm{ZnMgSSe}$ as the cladding layer. ${ }^{9}$

$\mathrm{ZnMgSSe}$ films of the zinc-blende structure can be grown on GaAs (001) substrates, and the band gap energies can be changed from 2.8 to $4 \mathrm{eV}$ maintaining lattice matching to the GaAs substrates. ${ }^{3}$ However it is reported that the crystalline quality of $\mathrm{ZnMgSSe}$ layers tends to be worse with the increase of the Mg composition. For binary Mg chalcogenides of the zinc-blende structure, the lattice constants of 5.89 and $5.62 \AA$ and the band gap energies of 3.6 and $4.5 \mathrm{eV}$ are estimated for $\mathrm{MgSe}$ and $\mathrm{MgS}$, respectively. ${ }^{3}$ However the binary compound $\mathrm{MgS}$ naturally forms the rocksalt structure, and the reported lattice constants and bandgap energies were extrapolated from the experimental data on the quaternary alloys.

Although the zinc-blende $\mathrm{MgS}$ has not previously been reported, the largest band gap among II-VI semiconductors is estimated in MgS. Therefore in the combination of $\mathrm{ZnSe}$ and $\mathrm{MgS}$, the band offsets of the conduction band and the valence band are expected to be very large. ${ }^{10}$ This will offer large quantum confinement effects on both electrons and holes. In addition, $\mathrm{ZnSe} / \mathrm{MgS}$ heterostructures will have small lattice mismatch of $0.87 \%$ and are reasonably latticematched to GaAs substrates. These attractive features motivate us to try to grow the zinc-blende MgS. In this letter, we report the first successful epitaxy of zinc-blende $\mathrm{ZnSe} / \mathrm{MgS}$ SLs on GaAs (001) substrates.
The growth apparatus used in the present experiment was an atmospheric-pressure metalorganic vapor phase epitaxy (MOVPE) system. ZnSe/MgS SLs were grown on semiinsulating (S.I.) GaAs (001) substrates. The precursors used were diethylzinc (DEZn), diethylselenide (DESe), bismethylcycropentadienyl-magnesium $\left[(\mathrm{MeCp})_{2} \mathrm{Mg}\right]$ and diisopropylsulfide (DiPS). The flow rates were controlled by mass flow controllers. The line of the $\mathrm{Mg}$ precursor was heated to about $70{ }^{\circ} \mathrm{C}$, since the vapor pressure of $(\mathrm{MeCp})_{2} \mathrm{Mg}$ is low. Typical growth conditions are summarized in Table I.

The growth processes on the substrate surface were monitored by a He-Ne laser $(6328 \AA)$ using an optical multiple reflection in the films. This technique has been utilized to measure the film thickness and the growth rate. The fabricated $\mathrm{ZnSe} / \mathrm{MgS}$ SLs were characterized by high-resolution $\mathrm{x}$-ray diffraction (HRXRD) measurements utilizing a $\mathrm{Cu} K \alpha_{1}$ line $(\lambda=1.5406 \AA)$ and photoluminescence (PL) measurements at $12 \mathrm{~K}$. The specimens were excited by a $\mathrm{He}-\mathrm{Cd}$ laser $(3250 \AA)$.

The thick solid line shown in Fig. 1 is a typical (004) $\mathrm{x}$-ray diffraction pattern measured on the $\mathrm{ZnSe} / \mathrm{MgS}$ SL with 21 periods (sample a). Several orders of satellite peaks which reflect the periodicity in the SL are clearly observed. The 0th peak is observed at the higher angle position compared to the GaAs (004) diffraction peak. The average lattice constant perpendicular to the interface $\left(a_{\perp \text { av }}\right)$ was calculated to be $5.607 \AA$.

We have examined the dependence of the 0th peak position on the rotation angle in the (001) surface plane during the HRXRD measurements. The variation of the corresponding $a_{\perp \text { av }}$ value by the rotation was within the accuracy of the apparatus, $0.001 \AA$. Therefore it is concluded that the SL (001) planes are almost completely parallel to the (001) plane of the GaAs substrate.

TABLE I. Typical growth conditions of ZnSe/MgS SLs.

$\begin{array}{ll}\text { Substrate temperature } & 490{ }^{\circ} \mathrm{C} \\ \text { DEZn flow rate } & 2.1 \mu \mathrm{mol} / \mathrm{min} \\ \text { DESe flow rate } & 1 \mu \mathrm{mol} / \mathrm{min} \\ (\mathrm{MeCP})_{2} \mathrm{Mg} \text { flow rate } & 0.37-0.56 \mu \mathrm{mol} / \mathrm{min} \\ \text { DiPS flow rate } & 16 \mu \mathrm{mol} / \mathrm{min} \\ \text { Growth rate of } \mathrm{ZnSe} & 0.43-0.48 \mu \mathrm{m} / \mathrm{h} \\ \text { Growth rate of } \mathrm{MgS} & 0.26-0.30 \mu \mathrm{m} / \mathrm{h}\end{array}$




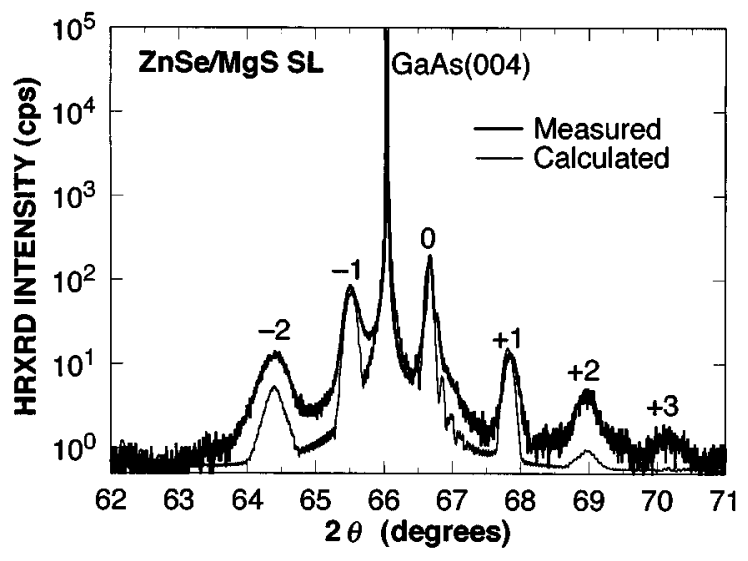

FIG. 1. X-ray diffraction pattern measured on a $\mathrm{ZnSe} / \mathrm{MgS}$ SL with the 21 periods. Several orders of satellite peaks indicated by $0, \pm 1, \pm 2$, and +3 were observed around the GaAs (004) peak. The thin solid line is the theoretical simulation calculated with the measured parameters.

The observed satellite peak positions were plotted in the form of $\sin \theta$ in Fig. 2. The linear relation to the order of the peaks shows the clear evidence that the observed peaks were diffracted from the SL structure. From this slope, the thickness in one period $(L)$ was estimated to be $92.4 \AA$. These observations of the well-defined SL satellite peaks around the GaAs (004) peak demonstrate the successful growth of zinc-blende $\mathrm{ZnSe} / \mathrm{MgS}$ SLs.

To determine the $\mathrm{ZnSe}$ well and $\mathrm{MgS}$ barrier layer widths from the HRXRD measurements, the precise knowledge of the lattice constants and the elastic constants is necessary to take into account the strain effects. However, these data are not available for the zinc-blende $\mathrm{MgS}$ at present. Therefore we have introduced another information on the layer widths from the in situ optical multiple reflection measurements. The reflection of the $\mathrm{He}-\mathrm{Ne}$ laser light gives the maximum and the minimum depending on the film thicknesses. Near the average level of the reflections, the variation of the reflection with the film growth is almost proportional to the change of the optical path length induced by the increase of the film thickness. Therefore, the ratio of the reflection intensity change during the growth of the $\mathrm{ZnSe}$ $\left(\Delta r_{\mathrm{ZnSe}}\right)$ and $\mathrm{MgS}\left(\Delta r_{\mathrm{MgS}}\right)$ layers is given by

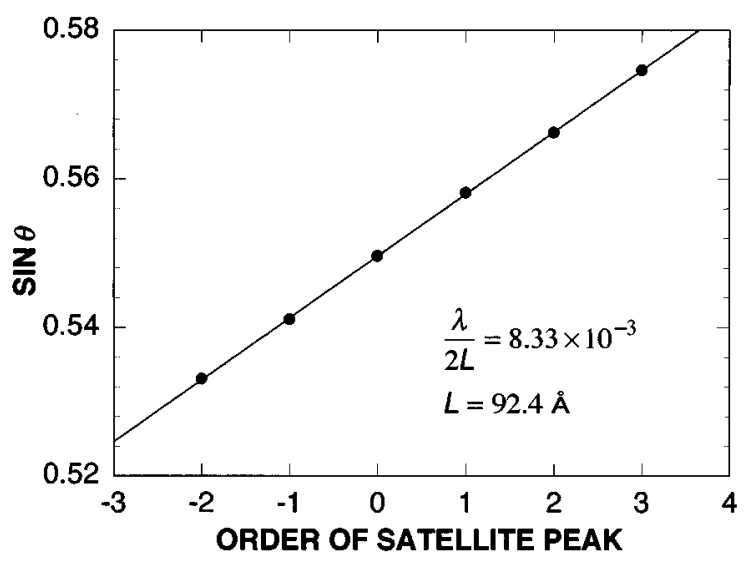

FIG. 2. The satellite peak positions observed in Fig. 1 were plotted in the form of $\sin \theta$. The thickness in one period $L$ was estimated to be $92.4 \AA$ from the slope.
TABLE II. Parameters measured on the samples a and $b$ : average lattice constant perpendicular to the interface $a_{\perp \text { av }}$, thickness in one period $L, \mathrm{ZnSe}$ well width $L_{\mathrm{ZnSe}}, \mathrm{MgS}$ barrier width $L_{\mathrm{MgS}}$. $M$ is the number of SL periods.

\begin{tabular}{ccrccc}
\hline \hline Sample & $\begin{array}{c}a_{\perp \mathrm{av}} \\
(\AA)\end{array}$ & $L(\AA)$ & $\begin{array}{c}L_{\mathrm{ZnSe}} \\
(\AA)\end{array}$ & $\begin{array}{c}L_{\mathrm{MgS}} \\
(\AA)\end{array}$ & $M$ \\
\hline $\mathrm{a}$ & 5.607 & 92.4 & 49.8 & 42.6 & 21 \\
$\mathrm{~b}$ & 5.617 & 113.0 & 69.4 & 43.6 & 20 \\
\hline \hline
\end{tabular}

$\Delta r_{\mathrm{ZnSe}} / \Delta r_{\mathrm{MgS}}=n_{\mathrm{ZnSe}} L_{\mathrm{ZnSe}} / n_{\mathrm{MgS}} L_{\mathrm{MgS}}$, where $n_{\mathrm{ZnSe}}$ and $n_{\mathrm{MgS}}$ are the refractive indexes of $\mathrm{ZnSe}$ and $\mathrm{MgS}$, respectively, and $L_{\mathrm{ZnSe}}$ and $L_{\mathrm{MgS}}$ are the $\mathrm{ZnSe}$ and $\mathrm{MgS}$ layer thicknesses, respectively. The one period in the SL is given by $L=L_{\mathrm{ZnSe}}+L_{\mathrm{MgS}}$. Therefore the ratio of the layer thicknesses, $L_{\mathrm{ZnSe}} / L_{\mathrm{MgS}}$, can be obtained with the knowledge of the refractive index values. In our experiments at the wavelength of $6328 \AA, n_{\mathrm{ZnSe}}$ of 2.578 and $n_{\mathrm{MgS}}$ of 2.206 were estimated using the modified single-effective-oscillator model. ${ }^{11}$ From the measured ratio of $\Delta r_{\mathrm{ZnSe}} / \Delta r_{\mathrm{MgS}}=1.37$ for this specimen together with $L=92.4 \AA, L_{\mathrm{ZnSe}}$ and $L_{\mathrm{MgS}}$ are calculated to be 49.8 and $42.6 \AA$, respectively. The measurements were performed on other SL samples following the same procedure, and the result for one more sample is added in Table II. Although the two samples shown in Table II have the MgS thicknesses less than $50 \AA$, the growth of the zinc-blende $\mathrm{MgS}$ layers was observed up to at least $100 \AA$.

Figure 3 shows the dependence of $a_{\perp \text { av }}$ on the total layer thickness for two series of samples with the fixed $L_{\mathrm{ZnSe}} / L_{\mathrm{MgS}}$ ratio and the fixed number of SL periods $M$ with different layer thicknesses in one period $L$. The $L_{\mathrm{ZnSe}} / L_{\mathrm{MgS}}$ ratio is 1.17 and 1.59 for the closed circles and the closed triangles, respectively. $a_{\perp \text { av }}$ was kept almost constant at about $5.607 \AA$ for $L_{\mathrm{ZnSe}} / L_{\mathrm{MgS}}=1.17$ up to the thickness of $3200 \AA$ and was kept at about $5.617 \AA$ for $L_{\mathrm{ZnSe}} / L_{\mathrm{MgS}}=1.59$ up to the thickness of $3000 \AA$. However, $a_{\perp \text { av }}$ was reduced when the film thickness increased further. This suggests the onset of the lattice relaxation of the films beyond the respective film thicknesses. This result indicates

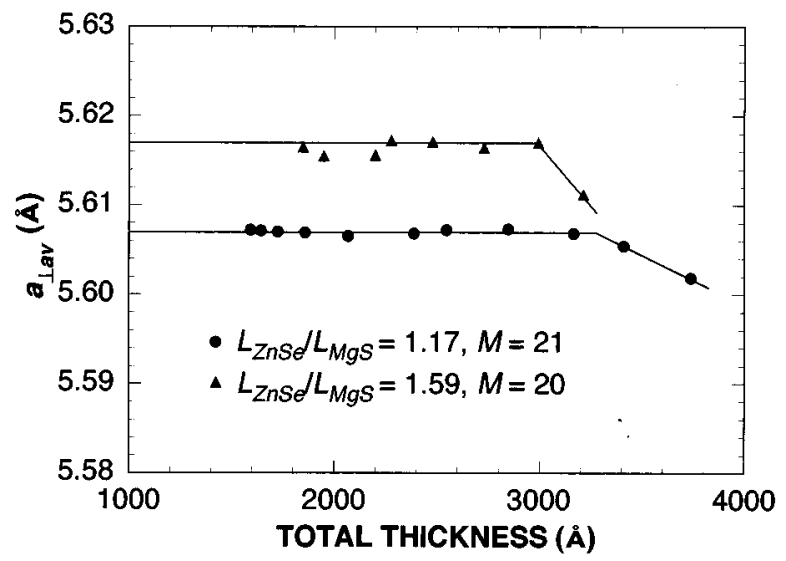

FIG. 3. Dependence of $a_{\perp \text { av }}$ on the total thickness for two series of samples with the fixed $L_{\mathrm{ZnSe}} / L_{\mathrm{MgS}}$ ratio and the fixed number of SL periods $M$, but with different layer thicknesses in one period $L . L_{\mathrm{ZnSe}} / L_{\mathrm{MgS}}$ and $M$ were 1.17 and 21 for the closed circles and 1.59 and 20 for the closed triangles. $a_{\perp \text { av }}$ was kept almost constant up to the total thicknesses of $3200 \AA$ for $L_{\mathrm{ZnSe}} / L_{\mathrm{MgS}}=1.17$ and $3000 \AA$ for $L_{\mathrm{ZnSe}} / L_{\mathrm{MgS}}=1.59$. $a_{\perp \text { av }}$ was reduced as the film thickness increased further. 


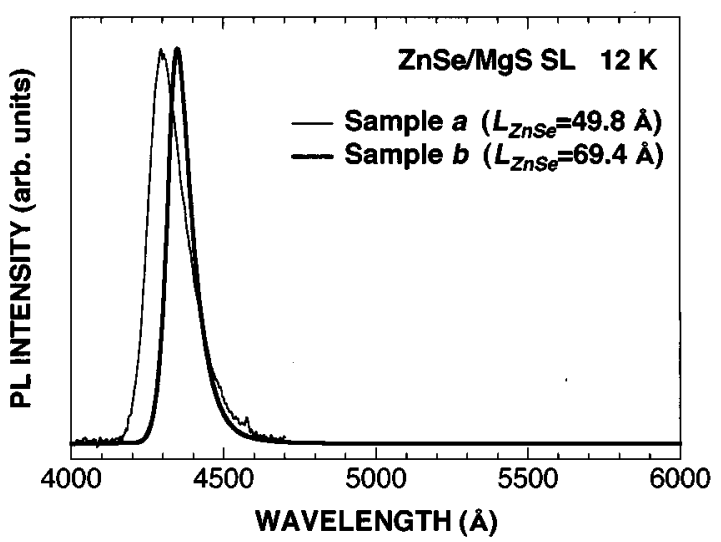

FIG. 4. PL spectra measured at $12 \mathrm{~K}$ on the $\mathrm{ZnSe} / \mathrm{MgS}$ SLs of the samples $a$ and $b$. The PL peaks were blue-shifted to the higher energy compared to that of bulk $\mathrm{ZnSe}$.

that the $\mathrm{ZnSe} / \mathrm{MgS}$ SL layers were grown coherently to the GaAs substrates up to the order of $3000 \AA$ in total thickness.

Let us discuss the lattice constant of the binary $\mathrm{MgS}$ $\left(a_{0 \mathrm{MgS}}\right)$. The lattice constants of $\mathrm{ZnSe}\left(a_{\perp \mathrm{ZnSe}}\right)$ and $\mathrm{MgS}$ $\left(a_{\perp \mathrm{MgS}}\right)$ perpendicular to the interface are related to the above-determined quantities in the following equation: $L / a_{\perp \mathrm{av}}=L_{\mathrm{ZnSe}} / a_{\perp \mathrm{ZnSe}}+L_{\mathrm{MgS}} / a_{\perp \mathrm{MgS}}$. In the $\mathrm{ZnSe} / \mathrm{MgS} \mathrm{SL}$ grown coherently on $(001) \mathrm{GaAs}, a_{\perp \mathrm{ZnSe}}=5.688 \AA$ is estimated from the condition of the pseudomorphic deformation of $\mathrm{ZnSe}$ on GaAs using the elastic constants for $\mathrm{ZnSe} .^{1} \mathrm{Em}-$ ploying the measured $a_{\perp \text { av }}, L, L_{\mathrm{ZnSe}}$, and $L_{\mathrm{MgS}}$ values summarized for the two samples in Table II, the $a_{\perp \mathrm{MgS}}$ was calculated to be $5.515 \AA$ for the sample a and $5.508 \AA$ for the sample b. Since the elastic constants for $\mathrm{MgS}$ is not available, we substitute those for $\mathrm{ZnSe}$ and $\mathrm{ZnS}{ }^{1}$ The $\mathrm{MgS}$ lattice constant derived was 5.590 and $5.592 \AA$ using the ZnSe and $\mathrm{ZnS}$ elastic constants, respectively, for the sample a. It was 5.587 and $5.589 \AA$ using the $\mathrm{ZnSe}$ and $\mathrm{ZnS}$ elastic constants, respectively, for the sample $\mathrm{b}$. From these results, the lattice constants of $\mathrm{MgS}$ was determined to be $a_{0 \mathrm{MgS}}=5.59 \AA$.

The credibility of the determined lattice constants and the layer thicknesses were examined by the theoretical simulation of the measured HRXRD pattern. The thin solid line in Fig. 1 shows the theoretical simulation calculated for the sample a. In this calculation, we take account of the thickness fluctuation for each layer to fit the broadening of the satellite peaks assuming the fluctuation of \pm 1 and \pm 2 monolayers with the respective diffraction weighting of 0.73 and 0.32. The excellent fit of the simulation to the measured pattern shows that the determined $a_{0 \mathrm{MgS}}$ value is well reliable.

Figure 4 shows PL spectra measured at $12 \mathrm{~K}$ on the $\mathrm{ZnSe} / \mathrm{MgS}$ SLs (samples a and b). The PL peaks were blueshifted to the higher energy compared to free-excitons of bulk $\mathrm{ZnSe}$ and no midgap emission was observed. The blue shift of the PL peaks was observed with the decrease of the thickness of well layers in SLs, which suggests the quantum confinement effect in the fabricated $\mathrm{ZnSe} / \mathrm{MgS}$ SLs.

In conclusion, we have demonstrated for the first time the successful growth of zinc-blende $\mathrm{ZnSe} / \mathrm{MgS}$ SLs. The SLs were grown coherently to GaAs substrates up to the total thickness of $\sim 3000 \AA$. The clear SL satellite peaks were observed in the HRXRD measurements and the lattice constant of MgS was estimated to be $5.59 \AA$.

This work was supported in part by a Grant-in Aid for Scientific Research from the Ministry of Education, Science, Sports and Culture, No. 07455126 and the Mitsubishi Foundation.

${ }^{1}$ K. Shahzad, D. J. Olego, and C. G. Van de Walle, Phys. Rev. B 38, 1417 (1988).

${ }^{2}$ R. B. Bylsma, W. M. Becker, T. C. Bonsett, L. A. Kolodziejski, R. L. Gunshor, M. Yamanishi, and S. Datta, Appl. Phys. Lett. 47, 1039 (1985).

${ }^{3}$ H. Okuyama, K. Nakano, T. Miyajima, and K. Akimoto, Jpn. J. Appl. Phys. 30, L1620 (1991).

${ }^{4}$ J. M. Gaines, R. R. Drenten, K. W. Haberern, T. Marshall, P. Mensz, and J. Petruzzello, Appl. Phys. Lett. 62, 2462 (1993).

${ }^{5}$ D. C. Grillo, Y. Fan, J. Han, L. He, R. L. Gunshor, A. Salokatve, M. Hagerott, H. Jeon, A. V. Nurmikko, G. C. Hua, and N. Otsuka, Appl. Phys. Lett. 63, 2723 (1993).

${ }^{6}$ B. Qu'Hen, R. Helbing, W. S. Kuhn, J. E. Bourée, A. Lusson, and O. Gorochov, J. Cryst. Growth 145, 541 (1994).

${ }^{7}$ J. Suda, Y. Kawakami, S. Fujita, and S. Fujita, Jpn. J. Appl. Phys. 33, L290 (1994).

${ }^{8}$ W. Faschinger, R. Krump, G. Brunthaler, S. Ferreira, and H. Sitter, Appl. Phys. Lett. 65, 3215 (1994).

${ }^{9}$ N. Nakayama, S. Itoh, T. Ohta, K. Nakano, H. Okuyama, M. Ozawa, A. Ishibashi, M. Ikeda, and Y. Mori, Electron. Lett. 29, 1488 (1993).

${ }^{10}$ The band offsets of 0.67 and $1.01 \mathrm{eV}$ in the conduction and valence bands, respectively, are estimated from the simple common anion rule. The tight binding model on the other hand gives 1.00 and $0.68 \mathrm{eV}$ in the conduction and valence bands, respectively.

${ }^{11}$ M. A. Afromowitz, Solid State Commun. 15, 59 (1974). The parameters $E_{0}, E_{g}, E_{d}$ in the formula in the reference for $\mathrm{MgS}$ were given as $E_{0}=7.5 \mathrm{eV}$ (extrapolated from other II-VI semiconductors), $E_{g}=4.5 \mathrm{eV}$ (energy gap) and $E_{d}=27 \mathrm{eV}$ (hold the similar value among II-VI semiconductors). 